\title{
Gas Turbine Gas Path Fault Diagnosis based on Adaptive Nonlinear Steady-State Thermodynamic Model
}

\author{
Jingchao Li ${ }^{\mathrm{a}}$, Guoyin Zhanga , and Yulong Ying, \\ ${ }^{a}$ School of Computer Science and Technology, Harbin Engineering University, Harbin, 150001, China. \\ ${ }^{b}$ School of Energy and Mechanical Engineering, Shanghai University of Electric Power, Shanghai, 200090, China
}

\begin{abstract}
Gas turbine engines always run during poor working conditions that have high temperatures, high pressures, and high mechanical and thermal stress. Thus, the performance of the gas path components gradually degrades, leading to serious faults. So, the health status of the engine gas path components provides essential information for users and operators. Here, a new gas path analysis approach has been developed to predict gas turbine engine health status by using gas path measurements. The developed approach has been tested in seven test cases where the degradation of a model gas turbine engine similar to a three-shaft marine engine has been analyzed. The case studies have shown that the approach can accurately and quickly detect, isolate, and quantify the degradation of major engine gas path components with the existence of measurement noise. The test cases have also shown that the time cost by the approach is short enough for its potential application of online health monitoring.
\end{abstract}

Keywords: thermodynamic model; gas turbine; gas path analysis; fault diagnosis

(Submitted on December 20, 2017; Revised on February 2, 2018; Accepted on March 26, 2018)

(C) 2018 Totem Publisher, Inc. All rights reserved.

\section{Introduction}

Nomenclature:

GPA Gas path analysis

$\vec{z} \quad$ Gas path measurement parameter vector

$\vec{p} \quad$ Engine component performance parameter vector

$\vec{u} \quad$ Ambient and operating condition vector

$\vec{v} \quad$ Transducer measurement noise vector

SF Component health parameter

$G \quad$ Mass flow rate

n Rotational speed

P Pressure

T Temperature

$\omega \quad$ Shaft angular speed

I1 Low-pressure compressor shaft

$\mathrm{Ne} \quad$ Power

I2 High-pressure compressor shaft

\footnotetext{
* Corresponding author.

E-mail address: yingyulong060313@163.com
} 
V1 Volume between low-pressure compressor and high-pressure compressor

V2 Volume between high-pressure compressor and high-pressure turbine including the volume of combustor

V3 Volume between high-pressure turbine and lower pressure turbine

V4 Volume between lower pressure turbine and power turbine

$\rho \quad$ Density

Subscripts:

$\begin{array}{ll}\text { C } & \text { Compressor } \\ \text { FC } & \text { Flow capacity } \\ \text { deg } & \text { Degraded condition } \\ \text { B } & \text { Combustor } \\ \text { Eff } & \text { Isentropic efficiency } \\ \text { T } & \text { Turbine } \\ \text { H } & \text { High pressure } \\ \text { L } & \text { Low pressure } \\ \text { LC } & \text { Low-pressure compressor } \\ \text { HC } & \text { High-pressure compressor } \\ \text { HT } & \text { High-pressure turbine } \\ \text { MT } & \text { Low-pressure turbine } \\ \text { PT } & \text { Power turbine } \\ \text { f } & \text { Fuel flow }\end{array}$

Gas turbine engines have been widely applied in the fields of aviation industry, marine engineering, combined cycle power plants and so forth. Due to the poor working conditions of high temperature, high pressure, and high mechanical and thermal stress, the performance of gas path components may gradually degrade and easily lead to various degradation faults. Therefore, the current health status of the engine provides essential information for users and operators.

Nowadays, there are two major types of fault diagnostic techniques for a gas turbine engine: one is the traditional technique (e.g., vibration, debris monitoring, oil analysis, boroscope inspection, visual inspection, etc.) and the other is a gas path analysis (GPA) technique. Traditional techniques are widely applied to the assessment of physical-mechanical conditions within engine components (e.g., rotors, bearings, disks, etc.), while the GPA techniques are mostly used to estimate the overall performance of major engine components, such as the compressor, combustors, and turbines.

Many GPA techniques have been proposed to estimate the performance and health status for gas turbine engines. From the linear GPA method developed by Urban in the late 1960's [13], a series of GPA methods were proposed, such as an adaptive nonlinear GPA method [7], artificial neural networks[3], rule-based expert system and rule-based fuzzy expert system [11], and genetic algorithm [4,12,17]. The merit of artificial intelligence methods, such as neural network, rough set [14], Bayesian network $[9,10]$ and rule based expert system, is that they do not need a gas turbine performance model, as only the relation information between fault symptom and degradation is needed. They can easily isolate the faulty component. However, the accumulation of knowledge by experiments and experience is a costly and uneasy job, and the magnitudes of the detected faults are not easily obtained. Nowadays, thermodynamic performance models of faulty engines are widely used to explore the symptom-fault relationship [10].

Here, a new gas path analysis approach has been developed to estimate gas turbine engine health status by the usage of gas path measurements. The developed approach has been tested in seven test cases where the degradation of a model gas turbine engine similar to a three-shaft marine engine has been analyzed. Analysis and conclusions are made accordingly.

\section{Methodology}

Normally, the gas turbine engine's overall health status is represented by gas path component health parameters, i.e., compressor and turbine flow capacity indices and efficiency indices. However, this essential performance and health status information cannot be directly measured, and thus, cannot be easily monitored and diagnosed.

In the gas turbine operation, when some physically degraded problems of gas path components occur, the component performance parameters (e.g., pressure ratio, mass flow rate, and isentropic efficiency) change and cause the deviation of gas- 
path measurable parameters, such as temperatures, pressures and shaft rotational speeds, etc. [8]. Thus, the deviation of component performance parameters can be indicated by the deviation of gas path measurement parameters, and such deviation of component performance parameters may be due to varying ambient and operating conditions or engine performance degradation [6]. The thermodynamic relationship between engine gas path measurement parameters and engine component performance parameters can be represented with Equation (1).

$$
\vec{z}=f(\vec{p}, \vec{u})+\vec{v}
$$

Where $\vec{z}$ is the gas path measurement parameter vector, $\vec{p}$ is the engine component performance parameter vector, $\vec{u}$ is the ambient and operating condition vector, and $\vec{v}$ is the transducer measurement noise vector.

Therefore, the gas turbine gas path fault diagnosis is an inverse mathematical problem that obtains the deviation of engine component performance parameters $\Delta \vec{p}$ through the deviation of gas path measurement parameter $\Delta \vec{z}$ after measurement noise reduction and data pre-processing against deviated ambient and operating conditions. It further obtains the deviation of gas path component health parameters for assessment of engine overall health status, which indicates the shift of the characteristic curves on the component characteristic maps.

\subsection{Improved definition for engine health parameters}

When the level of degradation is small, it is always assumed that the characteristic maps of degraded components (i.e., compressors, combustors and turbines) will keep more or less the same shape as their original maps based on the fact that the geometries of gas path components do not change significantly after degradation. Then, the degradation of gas path components can be represented by the shift of the characteristic curves on the maps, and such shifts can be expressed by the component health parameters, such as compressor and turbine flow capacity indices and efficiency indices, as well as combustor efficiency index $[6,7,8]$.

For previous gas path analysis methods (e.g., approaches developed by authors [2,6,7]), health parameters for gas path components were defined using component absolute performance parameters (e.g., mass flow rate $G$ and rotational speed $n$ for compressor and turbine). When the gas path measurements are obtained at slightly different ambient conditions from baseline, they should be corrected to the baseline condition to eliminate the deviation of component performance parameters caused by varying ambient conditions (e.g., ambient temperature, pressure and humidity).

Here, in order to eliminate the inconvenience stated above, the health parameters for gas path components can be redefined using component similar performance parameters (e.g., corrected mass flow rate $G \sqrt{T \cdot R_{g}} / P$ and corrected rotational speed $n / \sqrt{T \cdot R_{g}}$ for compressor and turbine), where the same treatment can be found in the treatment of characteristic maps for compressor and turbine [5].

Compressor health parameters:

$$
\begin{gathered}
S F_{\mathrm{C}, F C}=G_{C, c o r, \mathrm{deg}} / G_{C, c o r} \\
\Delta S F_{C, F C}=\left(G_{C, c o r, \mathrm{deg}}-G_{C, c o r}\right) / G_{C, c o r} \\
S F_{C, E f f}=\eta_{C, \mathrm{deg}} / \eta_{C} \\
\Delta S F_{C, E f f}=\left(\eta_{C, \mathrm{deg}}-\eta_{C}\right) / \eta_{C}
\end{gathered}
$$

Where $S F_{\mathrm{C}, F C}$ is the compressor flow capacity index; $G_{C, c o r \text {, deg }}$ is the compressor corrected flow capacity when the compressor is degraded; $G_{C, c o r}$ is the compressor corrected flow capacity when the compressor is healthy; $S F_{C, E f f}$ is the compressor isentropic efficiency index; $\eta_{C \text {,deg }}$ is the compressor isentropic efficiency when the compressor is degraded; $\eta_{C}$ is the compressor isentropic efficiency when the compressor is healthy. 
Combustor health parameter:

Combustor degradation can be represented with the degradation of combustor combustion efficiency.

$$
\begin{gathered}
S F_{B, E f f}=\eta_{B, \mathrm{deg}} / \eta_{B} \\
\Delta S F_{B, E f f}=\left(\eta_{B, \mathrm{deg}}-\eta_{B}\right) / \eta_{B}
\end{gathered}
$$

Where $S F_{B, E f f}$ is the combustor efficiency index; $\eta_{B, \text { deg }}$ is the combustion efficiency when the combustor is degraded; $\eta_{B}$ is the combustion efficiency when the combustor is healthy.

Turbine health parameters:

$$
\begin{gathered}
S F_{T, F C}=G_{T, c o r, \mathrm{deg}} / G_{T, c o r} \\
\Delta S F_{T, F C}=\left(G_{T, c o r, \mathrm{deg}}-G_{T, c o r}\right) / G_{T, c o r} \\
S F_{T, E f f}=\eta_{T, \mathrm{deg}} / \eta_{T} \\
\Delta S F_{T, E f f}=\left(\eta_{T, \mathrm{deg}}-\eta_{T}\right) / \eta_{T}
\end{gathered}
$$

Where $S F_{T, F C}$ is the turbine flow capacity index; $G_{T, c o r \text {, deg }}$ is the turbine corrected flow capacity when the turbine is degraded; $G_{T, c o r}$ is the turbine corrected flow capacity when the turbine is healthy; $S F_{T, E f f}$ is the turbine isentropic efficiency index; $\eta_{T, \text { deg }}$ is the turbine isentropic efficiency when the compressor is degraded; $\eta_{T}$ is the turbine isentropic efficiency when the compressor is healthy.

\subsection{Nonlinear Steady-state Thermodynamic Model}

In order to test the effectiveness of the proposed GPA approach, a model gas turbine engine similar to a marine engine has been used. It is a three-shaft gas turbine with a low-pressure compressor (LC), a high-pressure compressor (HC), a combustor, a high-pressure turbine (HT), a low-pressure turbine (MT) and a power-turbine (PT). The propeller is connected to the power turbine by the reduction gear box as shown in Fig 1.

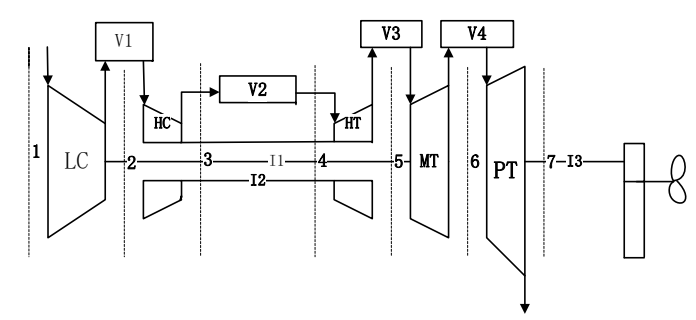

Figure 1. The schematic diagram of the model gas turbine engine

The total thermodynamic characteristics of this three-shaft gas turbine are mainly decided by all kinds of rotational inertias and volume inertias. The motion equations of rotor and volume of this engine were established as follows according to momentum balance and flow capacity balance $[15,16]$ :

$$
\begin{aligned}
& \mathrm{I} 1 \cdot \omega_{H} \frac{d \omega_{H}}{d t}=N e_{H T}-N e_{H C} \\
& \mathrm{I} 2 \cdot \omega_{L} \frac{d \omega_{L}}{d t}=N e_{M T}-N e_{L C}
\end{aligned}
$$




$$
\begin{aligned}
& \mathrm{V} 1 \cdot \frac{d \rho_{L H C}}{d t}=G_{L C_{\text {out }}}-G_{H C_{\text {in }}} \\
& \mathrm{V} 2 \cdot \frac{d \rho_{B}}{d t}=G_{H C_{o u t}}+G_{f}-G_{H T_{\text {in }}} \\
& \mathrm{V} 3 \cdot \frac{d \rho_{H M T}}{d t}=G_{H T_{\text {out }}}-G_{M T_{\text {in }}} \\
& \mathrm{V} 4 \cdot \frac{d \rho_{M P T}}{d t}=G_{M T_{\text {out }}}-G_{P T_{\text {in }}}
\end{aligned}
$$

Where I1 is the low-pressure compressor shaft; I2 is the high-pressure compressor shaft; V1 is the volume between low-pressure compressor (LC) and high-pressure compressor (HC); V2 is the volume between high-pressure compressor (HC) and high-pressure turbine (HT) including the volume of combustor (B); V3 is the volume between high-pressure turbine (HT) and lower-pressure turbine(MT); V4 is the volume between lower-pressure turbine (LT) and power turbine (PT); $\omega_{H}$ is the high-pressure compressor shaft angular speed; $\omega_{L}$ is the low-pressure compressor shaft angular speed; $N e_{H T}$ is the high-pressure turbine power; $N e_{H C}$ is the high-pressure compressor power; $N e_{P T}$ is power turbine power; $N e_{M T}$ is the lowerpressure turbine power; $N e_{L C}$ is the lower-pressure compressor power; $\rho_{B}$ is the mean gas density in combustion, $G_{H C_{o u t}}$ is the high-pressure compressor outlet air flow, $G_{H_{T i}}$ is the high-pressure turbine inlet gas flow, $\rho_{H M T}$ is the gas density between high-pressure turbine (HT) and low-pressure turbine (MT), $\rho_{M P T}$ is the gas density between low-pressure turbine (MT) and power turbine (PT), $G_{H T_{o u}}$ is the high-pressure turbine outlet gas flow, $G_{P T_{i n}}$ is the power turbine inlet gas flow, $G_{f}$ is fuel flow.

The above set of equations from Equation (12) to (17) are the dynamic mathematical model of this three-shaft gas turbine. When the gas turbine runs steadily, all thermodynamic parameters do not change with time, and the above set of equations from (12) to (17) will be algebraic equations, which means it reaches momentum balance and flow capacity balance, as shown below:

$$
\begin{gathered}
N e_{H T}=N e_{H C} \\
N e_{M T}=N e_{L C} \\
G_{L C_{\text {out }}}=G_{H C_{\text {in }}} \\
G_{H C_{\text {out }}}+G_{f}=G_{H T_{\text {in }}} \\
G_{H T_{\text {out }}}=G_{M T_{\text {in }}} \\
G_{M T_{\text {out }}}=G_{P T_{\text {in }}}
\end{gathered}
$$

The above set of equations from Equation (18) to (23) are the steady-state mathematical model of this three-shaft gas turbine engine.

\subsection{Nonlinear Newton-Raphson Method}

For a known residual equation set $\vec{E}=f(\vec{X})$, when variables $\vec{X} \in R^{n}$ change a small magnitude $\Delta \vec{X}$, corresponding residual vectors change a small magnitude $\Delta \vec{E}$ consequently. If the $\Delta \vec{X}$ is small enough, the relationship between $\Delta \vec{E}$ and $\Delta \vec{X}$ can be expressed by Equation (24) with adequate accuracy below: 


$$
\begin{gathered}
\Delta E=J(\vec{E}, \vec{X}) \cdot \Delta X, \\
\overrightarrow{E_{2}}-\overrightarrow{E_{1}}=J(\vec{E}, \vec{X}) \cdot\left(\overrightarrow{X_{2}}-\overrightarrow{X_{1}}\right)
\end{gathered}
$$

Where $J(\vec{E}, \vec{X})$ is the Jacobean matrix and

$$
J(\vec{E}, \vec{X})=\left(\begin{array}{l}
\frac{\partial E_{1}}{\partial x_{1}}, \frac{\partial E_{1}}{\partial x_{2}}, \ldots, \frac{\partial E_{1}}{\partial x_{n}} \\
\frac{\partial E_{2}}{\partial x_{1}}, \frac{\partial E_{2}}{\partial x_{2}}, \ldots, \frac{\partial E_{2}}{\partial x_{n}} \\
\cdots \\
\frac{\partial E_{m}}{\partial x_{1}}, \frac{\partial E_{m}}{\partial x_{2}}, \ldots, \frac{\partial E_{m}}{\partial x_{n}}
\end{array}\right)
$$

When we choose an initial set of values $\overrightarrow{X_{1}}$, the residual equation set produces a residual vector $\overrightarrow{E_{1}}$. We hope that when obtaining the next iterative point $\overrightarrow{X_{2}}$, the corresponding residual vector $\overrightarrow{E_{2}}$ will be zero, which can be expressed by Equation (21) below:

$$
\overrightarrow{X_{2}}=\overrightarrow{X_{1}}-J^{-1}(\vec{E}, \vec{X})_{\vec{X}=\bar{X}_{1}} \cdot \overrightarrow{E_{1}}
$$
below:

Taking Equation (20) as a generalization, the nonlinear Newton-Raphson method can be obtained as Equation (22)

$$
\overrightarrow{X_{k+1}}=\overrightarrow{X_{k}}-J^{-1}(\vec{E}, \vec{X})_{\vec{X}=X_{k}} \cdot \overrightarrow{E_{k}}
$$

Until the residual norm $\left\|\overrightarrow{E_{k+1}}\right\|<\varepsilon$, where $\varepsilon$ is specified precision, the final solution $\overrightarrow{X_{k+1}}$ can be obtained.

To ensure a unique solution of final solution $\overrightarrow{X_{k+1}}$, it is required that $\mathrm{n}=\mathrm{m}$. However, in practical applications of the gas path analysis method, $n$ may not be equal to $m$. If $n>m$ Equation (24) is under-determined and such a situation results in an infinite number of least squares solutions. A pseudo inverse can be defined as

$$
J(E, X)^{\#}=J(E, X)^{T} \cdot\left(J(E, X) \cdot J(E, X)^{T}\right)^{-1}
$$

The solution resulting from the pseudo inverse is best in a least squares sense.

If $\mathrm{n}<\mathrm{m}$, Equation (24) is over-determined and there are redundant equations. A pseudo inverse can be defined as

$$
J(E, X)^{\#}=\left(J(E, X)^{T} \cdot J(E, X)\right)^{-1} \cdot J(E, X)^{T}
$$

The resulting solution of Equation (24), $\overrightarrow{X_{k+1}}=\overrightarrow{X_{k}}-J^{\#}(\vec{E}, \vec{X})_{\vec{X}=\bar{X}_{k}} \cdot \overrightarrow{E_{k}}$, is also the best in a least-squares sense.

\subsection{The proposed GPA procedure}

For the previous gas path analysis method, (e.g., approaches developed by authors $[2,6,7]$ ), because the gas path component performance parameters are adaptive parameters, two steps should be included where the first step is to estimate engine degraded component performance parameters $\vec{p}$ using a performance adaption technique with gas path measurements, and the second step is to estimate component health parameters $\Delta \overrightarrow{S F}$ by comparing healthy and degraded performances at the component level to obtain the magnitude of shift of the characteristic curves on component' maps due to degradation. Here, a 
new GPA approach has been developed to detect engine performance degradation by using gas path measurements $\vec{z}$ to directly output the deviations of component health parameters $\Delta \overrightarrow{S F}$. Then, the Equation (1) can be expressed by the following equation.

$$
\vec{z}=f(\vec{x}, \vec{u})+\vec{v}=f(\overrightarrow{m a p}, \Delta \overrightarrow{S F}, \vec{u})+\vec{v}
$$

A typical procedure of the new GPA for the estimation of gas turbine health status is shown in Figure 2

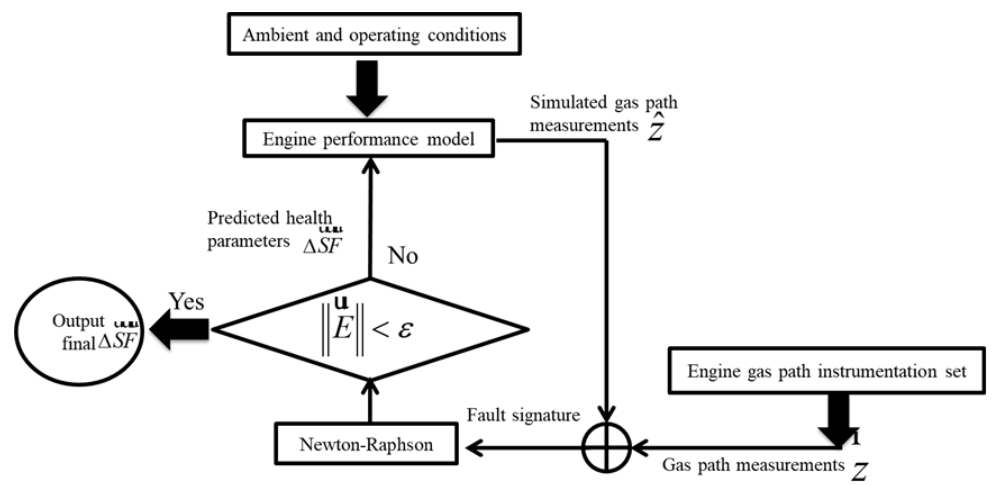

Figure 2. The schematic diagram of engine health status estimation based on adaptive nonlinear steady-state thermodynamic model

In the proposed GPA procedure, an accurate nonlinear steady-state thermodynamic performance model should be established for the gas turbine engine in concern at the start of engine operation based on advanced simulation software and engine gas path measurements. The performance of the gas turbine engine at such a condition is regarded as healthy engine performance, and the characteristic maps for gas path components (e.g., compressors, combustor and turbines) should accurately describe their performance behavior. In a gas turbine engine operation, engine gas path measurements are obtained continuously and are used to estimate the deviation of gas path component health parameters $\Delta \overrightarrow{S F}$ for assessment of engine overall health status due to engine degradation.

For the previous GPA method, in order to compare the gas path measurements between healthy and degraded conditions, the measurements should be obtained at or corrected to the same ambient and operating condition. Here, due to the application of similar parameters for engine health parameters and characteristic maps for the compressor and turbine, the influence of deviation of component performance parameters caused by varying ambient and operating conditions on the estimation of engine health status can be automatically eliminated by just setting the same ambient and operating conditions for the engine steady-state model as that of the actual gas turbine engine operation.

Here $E_{i}=z_{i, \text { predicted }}-z_{i, \text { actual }}$ for the ith measurable parameter of the characteristic vector used for diagnosis.

A Newton-Raphson algorithm is used to search the optimal component health parameters $\Delta \overrightarrow{S F}$ for the degraded components. The convergence of the proposed GPA shown in Figure 3 is declared when the simulated gas path measurement parameters are very close to the actual measurement parameters (i.e., $\|\vec{E}\|<\varepsilon$ and here $\varepsilon=0.001$ ).

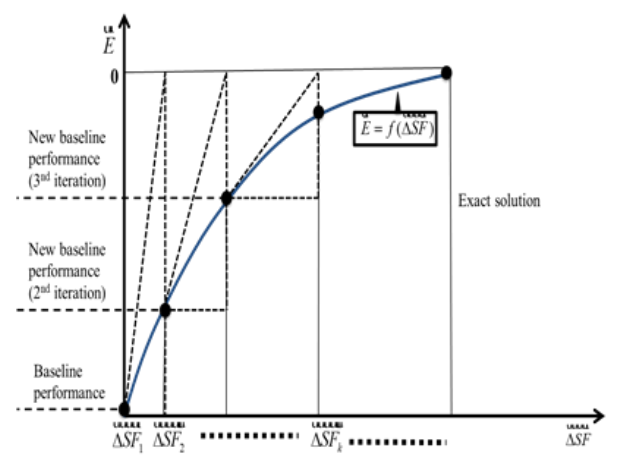

Figure 3. The proposed GPA method 


\title{
3. Application and analysis
}

To test the effectiveness of the developed approach, a typical model gas turbine engine similar to a three-shaft marine engine is chosen for the demonstration of the proposed GPA. Its configuration and mathematical model has been introduced in section 2.2. When the engine operates at certain working conditions, the fuel supply flow rate is used as a control parameter and is kept constant when ambient condition changes and degradation. The basic performance specifications of the engine are as follows:

\author{
Total air flow rate $82.11 \mathrm{~kg} / \mathrm{s}$; \\ LC pressure ratio 4.57 ; \\ HC pressure ratio 4.53; \\ Output power $\quad 24265.1 \mathrm{~kW}$; \\ Thermal efficiency $34.94 \%$.
}

The engine steady-state thermodynamic model for the model gas turbine engine is created based on the simulation platform of MATLAB software. The input for engine steady-state model are ambient conditions (e.g., environmental temperature, pressure and air composition), fuel supply flow rate, fuel composition and fuel lower heating value, and the deviation of gas path component health parameters (for the start of engine operation). The outputs of the performance model are engine output power, total thermal efficiency, etc.

To test the proposed GPA approach for health status estimation, it is assumed that the compressors, the combustor and the turbines of the model engine may be degraded. The degradation of the engine is simulated by changing the deviation of the gas path components health parameters defined by Equations (3), (5), (7), (9) and (11). Seven engine degradation cases shown in Table 1 are used to test the improved GPA approach. The first six test cases have single component degradation and the seventh case has all major components degraded. The first six cases are used to test the ability of the proposed GPA approach in isolating a degraded component and further quantifying the degradation when only one component is degraded. The seventh case is used to test whether the approach can accurately estimate the engine degradation when all of the major components are degraded simultaneously. Once the simulated gas path measurements are collected, it is assumed that the implanted gas path component degradation is unknown. The simulated gas path measurements are used as the input to the proposed GPA system to test the ability in predicting the changing performance and health status for the gas turbine engine.

\begin{tabular}{|c|c|c|c|c|c|c|c|c|c|}
\hline \multicolumn{3}{|c|}{$\begin{array}{l}\text { Deviation of Health Status } \\
\text { Indices }\end{array}$} & Test Case1 & $\begin{array}{c}\text { Test } \\
\text { Case2 }\end{array}$ & $\begin{array}{c}\text { Test } \\
\text { Case3 }\end{array}$ & $\begin{array}{c}\text { Test } \\
\text { Case4 }\end{array}$ & $\begin{array}{c}\text { Test } \\
\text { Case5 }\end{array}$ & $\begin{array}{c}\text { Test } \\
\text { Case6 }\end{array}$ & $\begin{array}{c}\text { Test } \\
\text { Case7 }\end{array}$ \\
\hline & $\begin{array}{c}\text { Mark } \\
\text { No. }\end{array}$ & Symbols & \multicolumn{7}{|c|}{ Implanted Degradation (\%) } \\
\hline \multirow{2}{*}{$L C$} & 1 & $\Delta S F_{L C, E f f}$ & -2.0 & 0 & 0 & 0 & 0 & 0 & -2.0 \\
\hline & 2 & $\Delta S F_{L C, F C}$ & -3.0 & 0 & 0 & 0 & 0 & 0 & -3.0 \\
\hline \multirow{2}{*}{$H C$} & 3 & $\Delta S F_{H C, E f f}$ & 0 & -2.0 & 0 & 0 & 0 & 0 & -2.0 \\
\hline & 4 & $\Delta S F_{H C, F C}$ & 0 & -3.0 & 0 & 0 & 0 & 0 & -3.0 \\
\hline$B$ & 5 & $\Delta S F_{B, E f f}$ & 0 & 0 & -2.0 & 0 & 0 & 0 & -2.0 \\
\hline \multirow{2}{*}{$H T$} & 6 & $\Delta S F_{H T, E f f}$ & 0 & 0 & 0 & -2.0 & 0 & 0 & -2.0 \\
\hline & 7 & $\Delta S F_{H T, F C}$ & 0 & 0 & 0 & -3.0 & 0 & 0 & -3.0 \\
\hline \multirow{2}{*}{$L T$} & 8 & $\Delta S F_{L T, E f f}$ & 0 & 0 & 0 & 0 & -2.0 & 0 & -2.0 \\
\hline & 9 & $\Delta S F_{L T, F C}$ & 0 & 0 & 0 & 0 & -3.0 & 0 & -3.0 \\
\hline \multirow{2}{*}{$P T$} & 10 & $\Delta S F_{P T, E f f}$ & 0 & 0 & 0 & 0 & 0 & -2.0 & -2.0 \\
\hline & 11 & $\Delta S F_{P T, F C}$ & 0 & 0 & 0 & 0 & 0 & -3.0 & -3.0 \\
\hline
\end{tabular}

The engine gas path instrumentation set for the analysis of the model engine is shown in Table 2. It is assumed that all gas path sensors are healthy (i.e., no measurement bias). The deviation of the engine gas path parameters may indicate degraded engine performance. The simulated samples of those parameters shown in Table 2 are collected and regarded as simulated gas path measurements. 
Table 2. Engine gas path instrumentation set

\begin{tabular}{|c|c|}
\hline Symbols & Parameters \\
\hline$P 0(\mathrm{MPa})$ & Ambient Pressure \\
\hline$T 0(\mathrm{~K})$ & Relative humidity \\
\hline$\phi(\%)$ & $L C$ inlet pressure \\
\hline$P 1(\mathrm{MPa})$ & $L C$ inlet temperature \\
\hline$T 1(\mathrm{~K})$ & Fuel flow rate \\
\hline$G f(\mathrm{~kg} / \mathrm{s})$ & $L C$ outlet pressure \\
\hline$P 2(\mathrm{MPa})$ & $L C$ outlet temperature \\
\hline$T 2(\mathrm{~K})$ & $H C$ outlet pressure \\
\hline$P 3(\mathrm{MPa})$ & $H C$ outlet temperature \\
\hline$T 3(\mathrm{~K})$ & $H T$ outlet pressure \\
\hline$P 5(\mathrm{MPa})$ & $H T$ outlet temperature \\
\hline$T 5(\mathrm{~K})$ & $L T$ outlet pressure \\
\hline$P 6(\mathrm{MPa})$ & $L T$ outlet temperature \\
\hline$T 6(\mathrm{~K})$ & $P T$ outlet temperature \\
\hline$T 7(\mathrm{~K})$ & $L T$ shaft rotational speed \\
\hline$n 1(\mathrm{r} / \mathrm{min})$ & $H T$ shaft rotational speed \\
\hline$n 2(\mathrm{r} / \mathrm{min})$ & \\
\hline
\end{tabular}

By implanting the various component degradations shown in Table 1 into an engine steady-state performance model, the deviations of gas path measurement (fault signatures) relative to the measurements when the engine is healthy in the seven test cases are shown in Table 3

Table 3. Measurement Deviations (i.e. Fault Signatures) in Seven Test Cases $(\mathrm{T} 0=288.15 \mathrm{~K}, \mathrm{P} 0=1 \mathrm{~atm}$ and $\mathrm{Gf}=1.62 \mathrm{~kg} / \mathrm{s}$ )

\begin{tabular}{|c|c|c|c|c|c|c|c|}
\hline \multirow{2}{*}{ Symbols } & \multicolumn{7}{|c|}{ Measurement Deviations(\%)(relative to the measurements when the engine is healthy) } \\
\cline { 2 - 7 } & Test Case1 & $\begin{array}{c}\text { Test } \\
\text { Case2 }\end{array}$ & $\begin{array}{c}\text { Test } \\
\text { Case3 }\end{array}$ & $\begin{array}{c}\text { Test } \\
\text { Case4 }\end{array}$ & Test Case5 & Test Case6 & Test Case7 \\
\hline$P 2(\mathrm{MPa})$ & 0.817778 & -0.41666 & 1.047335 & 0.060762 & -5.10023 & 4.129885 & 0.558622 \\
\hline$T 2(\mathrm{~K})$ & -0.12603 & -0.12751 & 0.322262 & 0.018624 & -1.53433 & 1.285783 & -0.20665 \\
\hline$P 3(\mathrm{MPa})$ & 0.467373 & 0.472797 & 1.437337 & -3.22237 & 0.202945 & 1.996108 & 1.40113 \\
\hline$T 3(\mathrm{~K})$ & -0.22072 & -0.22331 & 0.41736 & -0.91926 & 0.061387 & 0.581273 & -0.30924 \\
\hline$P 5(\mathrm{MPa})$ & 0.456081 & 0.461378 & 1.420713 & -0.01122 & -2.63991 & 1.580683 & 1.250091 \\
\hline$T 5(\mathrm{~K})$ & -0.4134 & -0.41823 & 0.639816 & 0.073253 & -0.82858 & -0.99754 & -1.85897 \\
\hline$P 6(\mathrm{MPa})$ & 0.399905 & 0.404554 & 1.26478 & -0.01609 & 0.301797 & -1.23707 & 1.022324 \\
\hline$T 6(\mathrm{~K})$ & -0.43494 & -0.44002 & 0.603728 & 0.041235 & -0.32941 & -1.65258 & -2.09757 \\
\hline$T 7(\mathrm{~K})$ & -0.55197 & -0.55842 & 0.325274 & 0.031499 & -0.4139 & -1.76965 & -2.79536 \\
\hline$n 1(\mathrm{r} / \mathrm{min})$ & -1.32114 & 0.432129 & 0.801746 & -0.01562 & 0.112634 & 1.824056 & 1.507981 \\
\hline$n 2(\mathrm{r} / \mathrm{min})$ & -0.2637 & -1.31393 & 0.409592 & -0.62594 & 2.610344 & -0.45569 & 1.105479 \\
\hline
\end{tabular}

Table 3 shows that different engine degradations induce various engine performance deviations reflected by different gas path measurement deviations. To test the approach, these sets of gas path measurements are input to the proposed GPA approach assuming that the degradation of the compressors, the turbines and the combustor is unknown.

Since measurement noise is inevitable in gas path measurements and because it has a negative effect on health status prediction, measurement noise is added on the simulated gas path measurements $\vec{z}$ to make the analysis more practical. The maximum measurement noise for various gas path measurement parameters was based on information provided by Dyson and Doel [1], as shown in Table 4.

Table 4. Maximum Measurement Noise [1]

\begin{tabular}{|c|c|c|}
\hline & Range & Typical Error \\
\hline$P$ & $3 \sim 45$ psia & $\pm 0.5 \%$ \\
& $8 \sim 460$ psia & $\pm 0.5 \%$ or 0.125 psia \\
& & whichever is greater \\
\hline$t$ & $-65 \sim 290^{\circ} \mathrm{C}$ & $\pm 3.3{ }^{\circ} \mathrm{C}$ \\
\hline & $290 \sim 1000^{\circ} \mathrm{C} 1$ & $\pm \sqrt{2.5^{2}+(0.0075 \cdot t)^{2}}$ \\
& $000 \sim 1300^{\circ} \mathrm{C}$ & $\pm \sqrt{3.5^{2}+(0.0075 \cdot t)^{2}}$ \\
\hline
\end{tabular}

To reduce the negative effect of measurement noise on diagnostic analysis, multiple gas path measurement samples are obtained in the simulation, and a 10-point rolling average [8] can be applied to get an averaged measurement sample before the measurements are input to the proposed GPA approach. The mathematical expression for the rolling average is shown in Equation (31). 


$$
\overline{z_{i}}=\frac{1}{P} \sum_{i=1}^{P} z_{i}
$$

Where $z_{i}$ is the gas path measurement samples, and $\mathrm{P}$ is the number of samples ( $\mathrm{P}=10$ for ten-point rolling average).

Measurement samples may be continuously obtained. The averaged sample at a specified time is the average of the last ten samples up to that moment. An instance of simulated measurement samples with and without data averaging and their comparisons with the true values are shown in Figure 4.

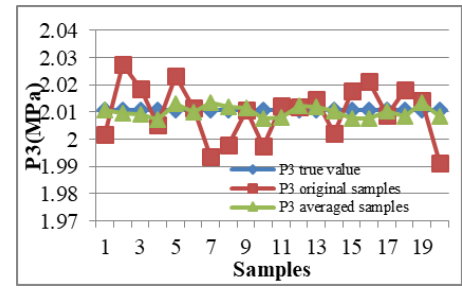

Figure 4. Comparisons between simulated measurement samples and true values for P3(MPa)

The corresponding nonlinear Newton-Raphson method can be expressed by equations below.

Known residual equation set

$$
\vec{E}=f(\vec{X})
$$

Where $\vec{E}=\left[E_{1}, E_{2}, E_{3}, E_{4}, E_{5}, E_{6}, E_{7}, E_{8}, E_{9}, E_{10}, E_{11}\right]$ is the residual equation vector, and $\vec{X}=\left[\Delta S F_{L C, F C}, \Delta S F_{L C, E f}, \Delta S F_{H C, F C}, \Delta S F_{H C, E f}, \Delta S F_{B, E F f}\right.$,

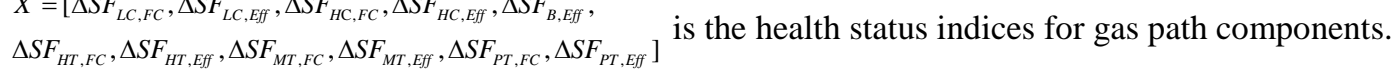

$$
\begin{gathered}
E_{1}=T_{2, \text { measured }}-T_{2, \text { predicted }} \\
E_{2}=T_{3, \text { measured }}-T_{3, \text { predicted }} \\
E_{3}=G_{L C_{\text {out }}}-G_{H C_{\text {in }}}
\end{gathered}
$$

Where the relationship between $P_{2, \text { measured }}$ and $P_{2, \text { predicted }}$ is underlying Equation (34)

$$
\begin{gathered}
E_{4}=T_{4, \text { measured }}-T_{4, \text { predicted }} \\
E_{5}=G_{H C_{\text {out }}}+G_{f}-G_{H T_{\text {in }}}
\end{gathered}
$$

Where the relationship between $P_{3, \text { measured }}$ and $P_{3, \text { predicted }}$ is underlying Equation (36).

$$
\begin{gathered}
E_{6}=T_{6, \text { measured }}-T_{6, \text { predicted }} \\
E_{7}=G_{H T_{\text {out }}}-G_{M T_{\text {in }}}
\end{gathered}
$$

Where the relationship between $P_{5, \text { measured }}$ and $P_{5, \text { predicted }}$ is underlying Equation (38).

$$
\begin{gathered}
E_{8}=T_{7, \text { measured }}-T_{7, \text { predicted }} \\
E_{9}=G_{M T_{\text {out }}}-G_{P T_{\text {in }}}
\end{gathered}
$$

Where the relationship between $P_{6, \text { measured }}$ and $P_{6, \text { predicted }}$ is underlying Equation (40).

$$
E_{10}=N_{e H T}-N_{e H C}
$$


Where the relationship between $n_{1, \text { measured }}$ and $n_{1, \text { predicted }}$ is underlying Equation (41).

$$
E_{11}=N_{e L T}-N_{e L C}
$$

Where the relationship between $n_{2, \text { measured }}$ and $n_{2, \text { predicted }}$ is underlying Equation (42).

Applying residual equation set $\vec{E}=f(\vec{X})$ into the nonlinear Newton-Raphson method, when the simulated steady-state solution $\hat{z}$ is close to the actual measurement parameters $\vec{z}$ and $\|\vec{E}\|<\varepsilon$, the convergence of engine health status estimation based on adaptive nonlinear steady-state thermodynamic model is declared, and the corresponding final health status indices $\Delta \overrightarrow{S F}$ for gas path components can be obtained.

\subsection{Test case 1 to 6}

In this study, the simulated engine performance with different engine component degradations is called an "actual performance", and the predicted engine performance by using the proposed GPA based on gas path measurements is called the "predicted performance".

The engine component degradations in the first six test cases predicted by the approach are shown in Figure 5 to Figure 10. The predicted degradation for major gas path components, i.e., the deviation of health parameters, were compared with the implanted component degradation.

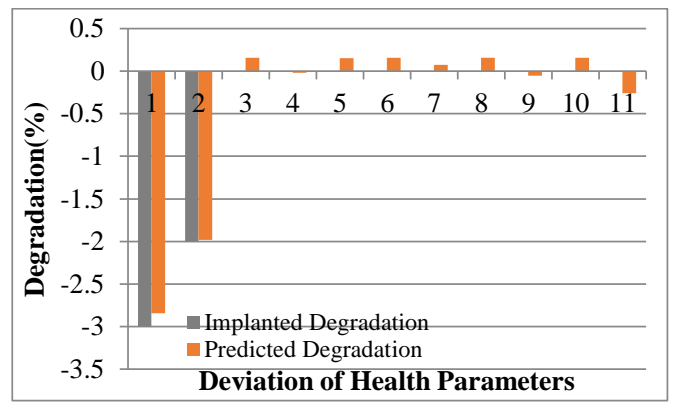

Figure 5. Predicted Degradation for Test Case 1

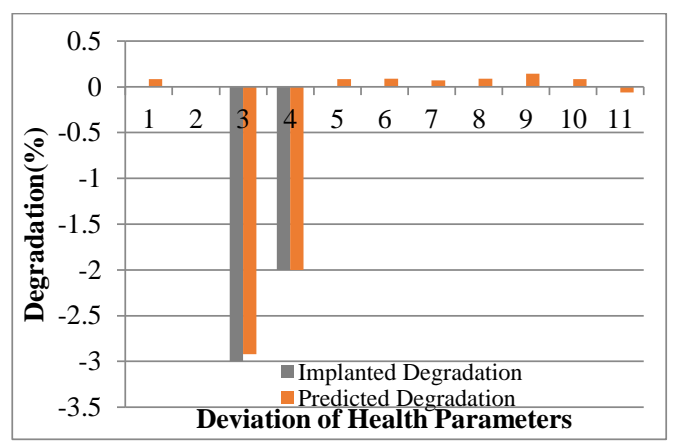

Figure 6. Predicted Degradation for Test Case 2

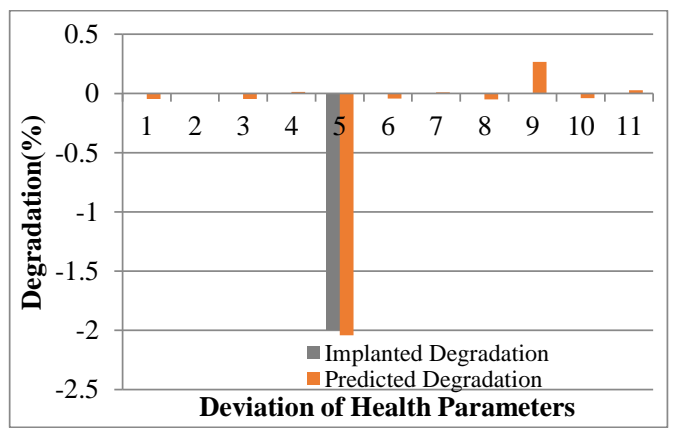

Figure 7. Predicted Degradation for Test Case 3 


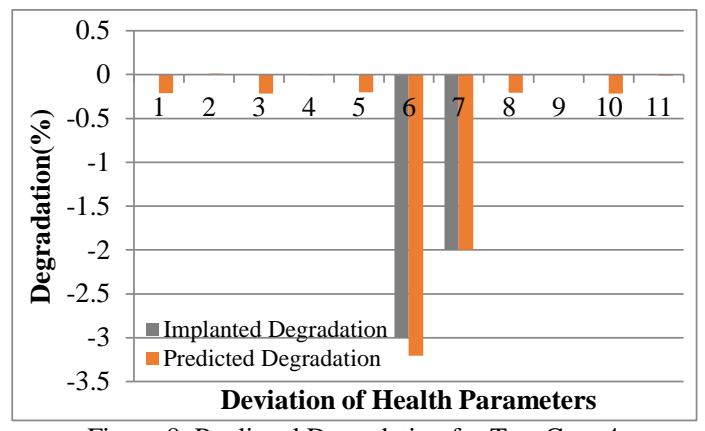

Figure 8. Predicted Degradation for Test Case 4

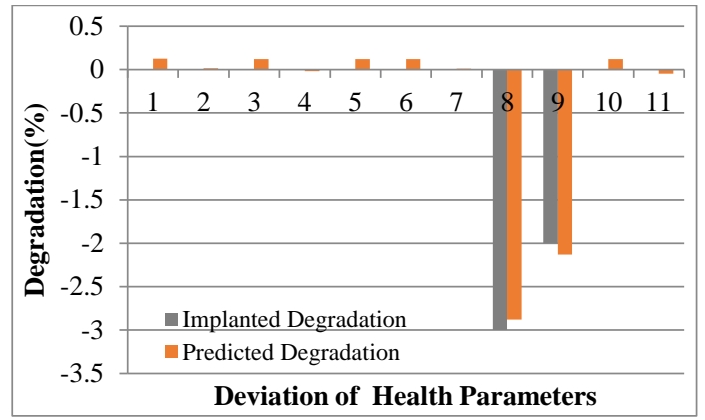

Figure 9. Predicted Degradation for Test Case 5

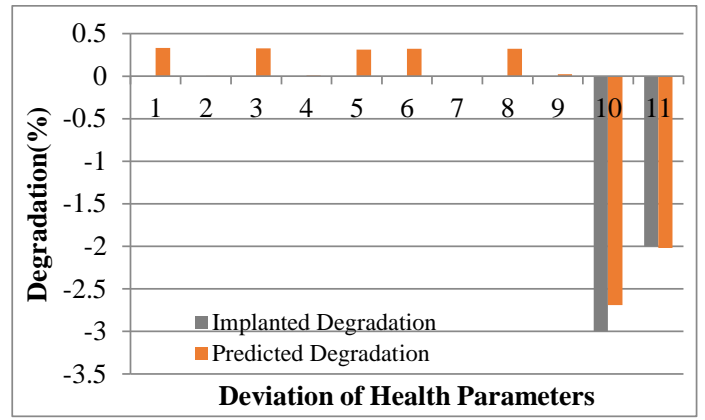

Figure 10. Predicted Degradation for Test Case 6

It can be seen that the prediction of gas path component degradation was accurate, indicating that the approach is able to search and isolate the degraded gas path components and further quantify the degradation when a single component degradation happens.

\subsection{Test case 7}

The engine component degradations in the seventh test case predicted by the approach are shown in Figure 11 . The predicted degradations for major gas path components were compared with the implanted component degradations.

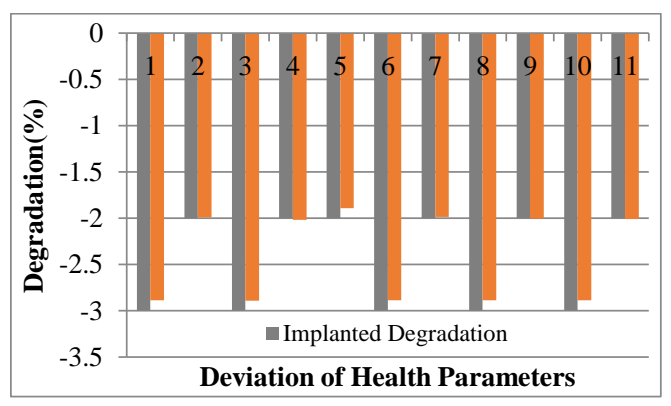

Figure 11. Predicted Degradation for Test Case 7

It can also be seen that the prediction of gas path component degradation was accurate, indicating that the approach is 
able to search and isolate the degraded gas path components and further quantify the degradation when multiple component degradations happen.

\subsection{Further Discussions}

From the test cases, it is interesting to see that because of the existence of random measurement noise, some small deviations of component health indices were predicted by the proposed GPA approach where the related gas path components were healthy. However, the magnitude of the pseudo deviations caused by measurement noise is small enough compared with that caused by degradation, and thus, the proposed GPA approach shows good tolerance to measurement noise.

Due to the simplification of the diagnostic analysis compared with previous adaptive gas path analysis methods, the time cost by the approach for one test case is only two seconds using a laptop computer with a $2.0 \mathrm{GHz}$ dual processor, which shows its potential application of online health monitoring for engines.

Because the model gas turbine chosen as the research object was a three-shaft marine gas turbine whose configuration is more complex compared to aircraft and power plant engines, the proposed GPA approach may have the potential application of health status estimation for other types of gas turbine engines.

\section{Conclusions}

Here, an improved adaptive gas path analysis approach has been developed to estimate gas turbine engine health status by using gas path measurements. The developed approach has been tested in seven test cases where the degradation of a model gas turbine engine similar to a three-shaft marine engine has been analyzed. Some conclusions have been obtained as follows:

(1) The proposed GPA approach can detect engine performance degradation by using gas path measurements to directly output component health parameters, which simplifies the procedure of diagnostic analysis.

(2) Due to the application of similar parameters for engine health parameters and characteristic maps for compressors and turbines, the influence of deviation of component performance parameters caused by varying ambient and operating conditions on the gas path diagnosis can be automatically eliminated.

(3) The approach can accurately and quickly detect, isolate, and quantify the degradation of major engine gas path components with the existence of measurement noise.

(4) The time cost by the approach is short enough for its potential application of online health monitoring.

(5) The developed approach may have the potential application of gas path diagnosis for other types of gas turbine engines.

\section{Acknowledgements}

This research is supported by the National Natural Science Foundation of China (No. 61603239)

\section{References}

1. R. J. E. Dyson and D. L. Doel, "CF-80 Condition Monitoring - The Engine Manufacturing's Involvement in Data Acquisition and Analysis", AIAA-84-1412, 1987.

2. E. L. Gatto, Y. G. Li and P. Pilidis, "Gas turbine off-design performance adaptation using a genetic algorithm," ASME Turbo Expo 2010: Power for Land, Sea, and Air, vol. 3, pp. 521-532, Glasgow, United kingdom, June, 2010.

3. M. F. A. Ghafir, Y. G. Li and L. Wang, "Creep Life Prediction for Aero Gas Turbine Hot Section Component Using Artificial Neural Networks," Journal of Engineering for Gas Turbines and Power, vol. 136, no. 3, pp. 1-9, 2014.

4. A. Gulati, M. Zedda, and R. Singh, "Gas Turbine Engine and Sensor Multiple Operating Point Analysis Using Optimization Techniques," 36th AIAA/ASME/SAE/ASEE Joint Propulsion Conference and Exhibit, pp. 3716, Huntsville, AL, United states, July, 2000.

5. E. Larsson, J. Aslund, E. Frisk and L. Eriksson, "Gas turbine modeling for diagnosis and control," Journal of Engineering for Gas Turbines and Power, vol. 136, no. 1, pp.1-8, 2014.

6. Y. G. Li, "A Genetic Algorithm Approach to Estimate Performance Status of Gas Turbines," ASME Turbo Expo 2008: Power for Land, Sea, and Air. American Society of Mechanical Engineers, vol.2, pp. 431-440, Berlin, Germany, June, 2008.

7. Y. G. Li, "Gas turbine performance and health status estimation using adaptive gas path analysis," Journal of engineering for gas turbines and power, vol. 132, no.4, pp. 1-9, 2010.

8. Y. Liu, M. Su. "Nonlinear Model Based Diagnostic of Gas Turbine Faults: A Case Study," ASME 2011 Turbo Expo: Turbine Technical Conference and Exposition. American Society of Mechanical Engineers, vol. 3, pp. 1-8, Vancouver, BC, Canada, June, 2011.

9. X. Pu, S. Liu and H. Jiang, "Sparse Bayesian Learning for Gas Path Diagnostics," Journal of Engineering for Gas Turbines and Power, vol. 135, no.7, pp.1-8, 2013.

10. F. Sahin and M. C. Yavuz, "Fault diagnosis for airplane engines using Bayesian networks and distributed particle swarm optimization," Parallel Computing, vol. 33, no.2, pp. 124-143, 2007. 
11. A. Salar, A. K. Sedigh and S. M. Hosseini, "A Hybrid EKF-Fuzzy Approach to Fault Detection and Isolation of Industrial Gas Turbines," ASME 2011 Turbo Expo: Turbine Technical Conference and Exposition. American Society of Mechanical Engineers, pp. 251-260, Vancouver, BC, Canada, June 2011.

12. D. L. Simon, J. B. Armstrong, "An integrated approach for aircraft engine performance estimation and fault diagnostics," Journal of Engineering for Gas Turbines and Power, vol. 135, no. 7, pp. 1-8, 2013.

13. L. A. Urban, "Gas Path Analysis Applied to Turbine Engine Condition Monitoring," J. Aircraft, vol. 10, no. 7, pp. 400-403, 1972.

14. L. Wang, Y. G. Li, M. F. Ghafir, "A Rough Set Diagnostic Frameworks for Gas Turbine Fault Classification," ASME Turbo Expo: Turbine Technical Conference and Exposition, pp. 1-6, San Antonio, June, 2013.

15. Y. L. Ying, Y. P. Cao and S. Y. Li, "Research on fuel supply rate of marine intercooled-cycle engine based on simulation experiment," International Journal of Computer Applications in Technology, vol. 48, no. 3, pp. 212-221, 2013.

16. Y. L. Ying, Y. P. Cao and S. Y. Li, "Study on flow parameters optimisation for marine gas turbine intercooler system based on simulation experiment," International Journal of Computer Applications in Technology, vol. 47, no. 1, pp. 57-67, 2013.

17. M. Zedda and R. Singh, "Gas Turbine Engine and Sensor Fault Diagnosis Using Optimization Techniques", AIAA Journal of Propulsion \& Power, Vol.18, No.5, pp.1019-1026, 2002. 